\title{
ResearchOnline@JCU
}

This is the AcceptedVersion of a paper published in the journal Biological Conservation:

Pressey, Robert L., Mills, Morena, Weeks, Rebecca, and Day, Jon C. (2013) The plan of the day: managing the dynamic transition from regional conservation designs to local conservation actions. Biological Conservation, 166. pp. 155169.

http://dx.doi.org/10.1016/j.biocon.2013.06.025 


\section{The plan of the day: managing the dynamic transition from regional conservation designs to local conservation actions}

Robert L. Pressey ${ }^{\mathrm{a},{ }^{*}}$, Morena Mills ${ }^{\mathrm{a}, \mathrm{b}}$, Rebecca Weeks ${ }^{\mathrm{a}, \mathrm{c}}$, Jon C. Day ${ }^{\mathrm{d}}$

${ }^{a}$ Australian Research Council Centre of Excellence for Coral Reef Studies, James Cook University, Townsville QLD 4811 Australia

b Present address: Global Change Institute, University of Queensland, Brisbane 4017, Australia

${ }^{c}$ Wildlife Conservation Society, Fiji Country Program, 11 Ma'afu Street, Suva, Fiji

${ }^{\mathrm{d}}$ Great Barrier Reef Marine Park Authority, PO Box 1379, Townsville QLD 4810 Australia

Keywords:

Conservation planning

Conservation actions

Implementation

Scale

Regional

Local

Private land

Near-shore marine waters

* Corresponding author. Tel.: +61 74781 6194; fax: +61 747816722.

Email addresses: bob.pressey@jcu.edu.au (R.L. Pressey), morena.mills@uq.edu.au (M. Mills), rebecca.weeks@jcu.edu.au (R. Weeks), j.day@gbrmpa.gov.au (J.C. Day) 


\section{ABSTRACT}

In numerous and important situations across the globe, the transition from designs to actions in conservation planning requires multiple iterations. Regional designs need to be updated progressively as some applied actions depart spatially from the areas notionally selected for conservation, or as some intended actions prove infeasible or undesirable. For researchers and organizations to fully capitalize on the enormous investment in conservation designs around the world, regional designs must be seen, not as static products, but as starting points for ongoing adaptation. We explain 18 reasons why regional designs need to be adapted, either in anticipation of actions or as actions are progressively applied. Our reasons are in four groups: early fine-tuning; mistakes and surprises; new data; and major overhaul. We show that the relative importance of these reasons varies between three planning situations: 1. rapid application, when conservation actions are applied simultaneously across all parts of regional designs; 2. protracted application, when, more typically, actions are applied incrementally over extended periods; and 3. revision of regional designs, either mandated or spontaneous. We then explore the conceptual, operational, institutional, and policy implications of designs being, or needing to be, dynamic. The weaknesses in methods for conservation planning are most starkly revealed by the need to adapt designs during protracted application of actions on private or community-managed lands and marine waters. 


\section{Introduction}

Systematic conservation planning involves sequential transitions between groups of decisions (Pressey and Bottrill 2009). Early in the process, stakeholders define goals, then goals determine what spatial data are needed. Later, spatial data inform decisions about quantitative objectives, and objectives guide the design of conservation areas. Then potential conservation areas on paper or computer screens must be turned into actions on the ground or in the water. This last transition, from regional designs to local actions, has been difficult for conservation planners because it requires reconciliation between two spheres of decisionmaking (Agardy 2005; Mills et al. 2010), and perhaps even two world views: one recognising the primacy and legitimacy of local decision making and one concerned with the dangers of parochialism and the benefits of wide perspectives (Knight et al. 2008; Noss 2010; Pressey and Bottrill 2009; Smith et al. 2009). Yet, both regional designs and local actions are crucial to achieving conservation goals, and both have complementary strengths and limitations.

We refer to "regional" as any spatial extent that provides broad perspective for decisions about individual conservation areas (Table 1). We define regional designs as systems of notional conservation areas that collectively achieve objectives (Pressey and Bottrill 2009). Regional designs have three main advantages. First, they incorporate relationships between individual areas, including complementarity (Margules and Pressey 2000) and connectivity (McCook et al. 2009), so that systems are more than the sums of their parts. Second, planners can explore spatial and temporal options for conservation, substituting areas in response to perceived threats, costs or opportunities (Green et al. 2009) and scheduling areas for action through time (Visconti et al. 2010). Third, designs can inform other initiatives with broader objectives but similar extents of concern, including land use planning (Pierce et al. 2005) and integrated coastal management (Cicin-Sain and Belfiore 2005). A key limitation of regional designs is their poor record of translation into local actions (Hviding 2006; Knight et al. 2008).

We refer to "local" as the extent of individual actions to protect, manage or restore biodiversity (Table 1). Local actions, typically not guided by regional designs (Knight et al. 2008), have two related advantages, especially when developed by local actors, including communities, non-government organisations, and private enterprises. First, they are 
motivated, understood and supported by the people most directly affected by the associated constraints on use of natural resources (Johannes 2002; Smith et al. 2009; Syakur et al. 2012). Second, they can be based on detailed information on biodiversity and socioeconomic variables (Aswani and Lauer 2006; Gadgil et al. 1993) that is impossible to collect consistently across most regions (Green et al. 2009). The limitations of local actions include their propensity to form collections rather than systems of complementary, functionally connected areas (Noss 2010; Weeks et al. 2010a) and their poor integration between land, sea and freshwater (Cicin-Sain and Belfiore 2005). Another serious limitation of many local actions, particularly when politicized, is their tendency toward landscapes or seascapes that are easiest to protect because they have few uses to compete with conservation but, as a consequence, least need for protection (Joppa and Pfaff 2009; Scott et al. 2001).

Like all transitions in the planning process, the one from regional designs to local actions should be iterative. Adjustments to designs will be necessary as new information emerges during implementation of actions, in turn altering areas of interest for later actions. Several reasons for feedback from actions to designs have been mentioned in the literature, including new data, revised objectives, adjustment from planning units (Table 1) to units of actual management, replacement of areas that prove unexpectedly difficult to protect, ongoing loss of biodiversity, and evaluation of implementation mechanisms (Cowling et al. 2003; Douvere 2008; Douvere and Ehler 2011; Goodman 2003; Grantham et al. 2010; Henson et al. 2009; Holness and Biggs 2011; Margules and Pressey 2000; Pressey and Bottrill 2009; Pressey et al. 2007; Pressey and Logan 1997, 1998; Pressey and Taffs 2001; Weeks and Jupiter 2013). Vane-Wright (1996) proposed the idea of an action register, with priorities updated according to changes in threats and available resources. Similar ideas were later expressed in methods for dynamic scheduling of conservation actions as threatening processes expand (e.g. Spring et al. 2010; Turner and Wilcove 2006; Visconti et al. 2010). Related to scheduling, the notion of "informed opportunism", or balancing strategic priorities with emerging opportunities for conservation (Noss et al. 2002), has been illustrated conceptually (Pressey and Bottrill 2008; Seddon et al. 2010) and applied in practice (Game et al. 2011). Operational models for conservation planning have explicitly recognized dynamic feedbacks between designs and actions (Álvarez-Romero et al. 2011; Cowling et al. 2008; Knight et al. 2006a). 
Missing from this literature is a comprehensive review of why and under what circumstances the dynamic transition from designs to actions is necessary. Also lacking is a discussion of the implications of this transition for the ways in which we conceptualize and apply conservation planning. These gaps reflect the larger problem of discontinuity in information and personnel between the design and action stages of planning (Knight et al. 2008). The premise of this paper is that conservation planning will be more effective if regional designs and local actions are better integrated to capitalize on their respective strengths and minimize their respective weaknesses. We review the reasons why designs must change in anticipation of actions or as actions proceed, and how these reasons vary between planning situations. We then explore the conceptual, operational, institutional, and policy implications of the dynamic interaction between designs and actions, and what these mean for improving approaches to conservation planning.

\section{Reasons for the dynamic interaction between regional designs and local actions}

Regional designs can be initiated through the policies and preferences of organisations (Groves et al. 2002; Osmond et al. 2010) or motivated by the limitations of uncoordinated local actions (Weeks et al. 2010a). Either way, the translation of designs into actions inevitably involves some alteration of those parts of designs not already spatially fixed. Most regional designs consist mainly of notional conservation areas configured around established and relatively immovable areas such as national parks (e.g. Cowling et al. 2003) or stewardship arrangements with landholders (Stoneham et al. 2003). There are many reasons why the notional parts of designs should change (Table 2, detail in online Appendix), and these reasons differ between three planning situations, below. The first situation involves rapid application of actions across whole regional designs, although the designs themselves can take varying lengths of time to develop. The second situation, much more typical than the first, involves protracted application of actions, with only a few parts of any design being implemented in any one year. The third situation involves revision of regional designs, either because of mandated review intervals or perceptions that previous designs are outdated. Table 1 contains a glossary of key terms. 


\subsection{Rapid application of actions}

Rapid application of actions across all parts of regional designs is feasible in marine regions without community ownership and tracts of public land with few management authorities. Local government zonings might be another widespread example. In this situation, adjustments to regional designs anticipate rather than respond to applications of actions. We outline two case studies, differing in the time taken to develop the designs. The first example is the Regional Forest Agreement process in New South Wales (Pressey 1998; Pressey et al. 2009), initiated by the New South Wales and Australian Governments and focused on public production forests. It was a sequence of intensive, participatory negotiations between 1996 and 2001, supported by interactive planning software, each culminating in regional designs being recommended to government, with enactment soon afterwards. The second example is the rezoning of the Great Barrier Reef Marine Park (Day 2011; Osmond et al. 2010), a region managed jointly by the Australian and Queensland Governments and used extensively for tourism and recreational and commercial fishing. The design process included extensive public consultation and collaboration with experts, extending from 1999 until enactment of new zoning in July 2004.

In the Regional Forest Agreements, each negotiation (design process) lasted for several weeks but followed extensive preparation of data sets and multi-lateral decisions about objectives and procedures. During and after the negotiations, three kinds of adjustment to the initial designs were intended to facilitate conservation actions (group 1 in Table 2). The first involved changes by experts, in the interests of feasibility, to indicative designs produced by inevitably limited regional data sets. Changes included avoiding areas with management liabilities because of weed infestations and avoiding areas important to the timber industry because of tree species and proximity to timber mills. Second, stakeholders used the interactive software to apply different context-specific design rules for different species, landscape settings, and degrees of conflict with logging (Pressey et al. 2009). Third, although the process used logging compartments (units of management) as planning units, there was some fine-tuning of management boundaries in the interests of future management.

The first three reasons for changing regional designs (Table 2) were also important in rezoning the Great Barrier Reef Marine Park (Lewis et al. 2003; Osmond et al. 2010). 
Experts in the Marine Park Authority interacted with the software selections to lock in or lock out some planning units or to make the inclusion of others more or less likely, depending on perceived difficulties of implementing no-take and other zones. Public consultations led to changes from automated design rules to context-specific design and adjustment of planning units (mostly hexagons) to form feasible management units (Fig. 1). Considerations included avoidance of commercial and recreational fishing areas and navigational ease of identifying boundaries of no-take zones. The five-year design process also made room for other reasons for change to apply. During the public consultation process, data on biodiversity and socio-economic attributes of specific areas were revised (group 2 in Table 2) and new regional data sets became available (group 3 in Table 2) that altered the design (Lewis et al. 2003; Osmond et al. 2010).

\subsection{Protracted application of actions}

On land and in near-shore marine regions, a second planning situation is probably much more extensive globally than the previous one. This situation involves development of regional designs followed by years or decades of incremental conservation action accompanied by incremental loss of biodiversity (Visconti et al. 2010). Even on public lands, application can be protracted. Potential conservation areas identified in State Forest in Tasmania by Jamie Kirkpatrick in 1979 (published by Kirkpatrick 1983) were not fully implemented until the late 1990s, even with sustained attention (Pressey 2002). However, probably the most important examples of situations involving protracted application are lands and coastal waters under private or customary tenure (Hviding 2006; Wilcove et al. 2004) or other arrangements for finely subdivided ownership or management (Weeks et al. 2010a). In these situations, there are three main constraints on applying actions completely, effectively and quickly: 1 . the high financial cost of purchasing areas, compensating for forgone uses, or providing incentives for conservation; 2. the high transaction costs of negotiation and adjusting designs to the satisfaction of perhaps many hundreds of owners and users (Keppel et al. 2012); and 3. the difficulty of designing regulations and incentives that distribute the costs and benefits of conservation actions equitably enough to secure broad acceptance (Adams et al. 2010; Weeks et al. 2010b).

Under these circumstances, planners should expect that the locations and types of progressively applied actions will often differ from the regional designs that motivated them, 
for all the reasons in Table 2. The process of applying actions, adjusting their locations and types to suit local circumstances, and securing them (at least in the short- or medium-term), will require designs to be altered, in turn altering areas of interest for subsequent actions (Fig. 2). Some of this dynamic interplay will come from the nature of designs as systems that incorporate complementarity, connectivity, and spatial adjustments to opportunities and constraints, causing localized design changes to propagate spatially. Notably, nearly all of the published references to this adaptive design process are theoretical. We know of only three case studies that have described dynamic designs in practice. For a single large conservation area, Naughton (2007) recounted multiple phases of zoning and rezoning to balance competing interests. Henson et al. (2009) described planning processes in Africa lasting 10-15 years, with reviews of the effectiveness of actions and subsequent adjustments to designs and actions. In a coastal area in Fiji, the boundaries of marine protected areas and traditionally managed tabu areas have been adjusted in response to reviews of effectiveness and new information on the resilience of coral reefs (Weeks and Jupiter 2013).

The reasons for changes to designs that apply consistently in the previous planning situation (group 1 in Table 2) are also relevant here, but will operate differently over longer planning horizons. The transition from planning units of grids or hexagons to management units will ideally proceed iteratively (Pressey and Logan 1998), with modified boundaries in parts of the design altering the achievement of objectives and requiring further adjustments to correct for shortfalls or surpluses. An example of the initial part of this process is described by Green et al. (2009) (Fig. 3) although, like some other designs that have initiated actions, theirs has not yet been adjusted to accommodate the mismatch between large hexagonal planning units and subsequent actions in smaller, irregular management units. Ideally, expert-based changes to selected planning units and decisions about context-specific design (Fig. 4) should also be iterative during protracted application.

By its nature, extending over years or decades, this situation allows for progressive adjustment of regional designs to mistakes and surprises (group 2 in Table 2). For example, as some data on biodiversity prove to be wrong, as they inevitably will when management units are visited on the ground (online Appendix), replacement of notional conservation areas within designs will be necessary. New data on biodiversity, collected by planning teams or other people (group 3 in Table 2), will also call for adjustments to designs (Rouget 
2003). Data on opportunities and constraints, including conservation costs, are likely to be highly uncertain and subject to revision during implementation. Although local opportunities for conservation action can be estimated and mapped (Knight et al. 2010; Mills et al. 2013), they will be subject to change in response to changes in ownership, management, markets and experiences with conservation organisations. Moreover, some windows of opportunity for conservation, created by political events or natural disasters, are impossible to predict. Among the reasons for revising spatial data on the costs of conservation are that consistency across large regions often requires cost data at resolutions larger than management units (Richardson et al. 2006) and cost variables that are tenuously related to those of direct interest (Weeks et al. 2010c). Costs of potential protected areas are also prone to variation as conservation actions are applied elsewhere (Armsworth et al. 2006) and as commodity markets emerge or expand (Brewer et al. 2013; Butler et al. 2009).

Mismatches between regional objectives and local objectives (Table 2) are also likely to require adjustments to regional designs, and might interact with other mistakes and surprises, such as unforeseen constraints and conservation actions unrelated to designs. In many regions, local aspirations might not rank nature conservation highly, favouring infrastructure, health and education (Mills et al. 2013). Many extensive planning exercises will overlap with plans developed over smaller extents, and having substantial local support even if not using systematic methods. For example, a regional conservation design being developed for the Southwest Australia Ecoregion (http://swaecoregion.org) overlays numerous plans by Natural Resource Management groups and local government authorities, and the process of reconciling the resultant diversity of aspirations and objectives is likely to take some years.

For all the reasons in groups 2 and 3 (Table 2), this planning situation ideally involves continual adaptation of regional designs to new regional and local information. This iterative process would ensure that, at any time, the notional, still not implemented, parts of regional designs were based on the best possible information. In principle, protracted application could also entail major overhaul (group 4, Table 2), although there is little literature to go on (but see Henson et al. 2009).

Among the surprises likely during protracted application (group 2 in Table 2) are actions applied outside priority areas identified by regional designs. Mismatches between actions 
and regional priorities identified by Cowling et al. (2003) in the Cape Floristic Region of South Africa (Fig. 5A) arose partly from the general tendency of designs to be suggestive rather than prescriptive. The reality in most regions is that conservation actions have motivations other than strategic prioritization. Among these are political and bureaucratic positioning that places little emphasis on the persistence of biodiversity, and preferences of communities or individual owners reflecting local perspectives. Another cause of the mismatches was the 2002 design's role in catalysing its own revision, below, by motivating subsequent generations of designs over smaller parts of the region (Fig. 5B), leading to new priorities being imperfectly aligned with previous ones.

\subsection{Revisions of regional designs}

Revisions of regional designs are likely to be motivated either by the perceived need to update the designs themselves, even if they have not been extensively applied (von Hase et al. 2010), or by assessing the effectiveness of actions guided by those previous designs (groups 3 and 4 in Table 2, Agardy 2005; Douvere and Ehler 2011). These motivations can arise spontaneously or from policy or legislation. Spontaneous revision of regional designs will not always proceed as quickly and effectively as in the Cape Floristic Region (Fig. 5B). In that region, although Cowling et al. (2003) expected regular updating of their design and revision of their objectives within five years (Pressey et al. 2003), a series of less extensive and higher-resolution designs followed even sooner. These new designs responded to the inability of the extensive 2002 exercise to adequately address local priorities. The subsequent, detailed designs were facilitated by South Africa's ready skill base - a close-knit community of ecologists, park managers, and spatial analysts (Holness and Biggs 2011) and the international funding attracted by the region's status as a global biodiversity hotspot. This combination of circumstances is rare. More often, the costs of regional designs (Bottrill and Pressey 2012), lack of skills, resistance from stakeholders, and lack of political appetite can delay reviews well after their need is recognized. Even in well resourced regions, replacing designs can take many years. The initial zoning scheme for the Great Barrier Reef, developed in the 1980s, was found in the mid-1990s not to be achieving its mandate for biodiversity protection but was not replaced until 2004 (Osmond et al. 2010).

Reviews of regional designs required by policy or legislation can take two forms. The first is periodic, complete reassessment. For reasons of cost, but also impacts on resource users, 
major overhauls of designs (group 4, Table 2) are infrequent. The Regional Forest Agreements in New South Wales, each based on a regional design, are 20-year agreements intended to give certainty to industry and communities (Musselwhite and Herath 2005). The initial zoning of Moreton Bay Marine Park in 1993 was required by legislation to be revised in 2007 (van de Geer et al. 2013). The minimum review interval for the 2004 rezoning of the Great Barrier Reef is seven years, but there is no maximum interval (Section 37 of the Great Barrier Reef Marine Park Act 1975) and, as yet, no serious discussion of another rezoning. A remarkably frequent mandated revision of a marine spatial plan (at least every five years) was stipulated by the Massachusetts Oceans Act of 2008 (Douvere and Ehler 2011). A second approach to reviewing designs allows fine-tuning within their overall spatial architecture. In the Great Barrier Reef Marine Park, adaptive management operates within the 2004 zones, using tools such as permits, plans of management, seasonal closures, and industry-specific agreements to provide flexibility in revising access and use, including tourism, shipping, and some fisheries (Day 2008; McCook et al. 2010).

\section{Implications of dynamic regional designs}

The relevance of regional designs applied rapidly, and their adjustment in anticipation of actions, seem straightforward. Similarly, although examples of mandated reviews of designs are hard to find, there are published examples of learning from successive designs in South Africa (Knight et al. 2011a; Knight et al. 2006b) and within WWF-US (Morrison et al. 2009) and The Nature Conservancy (Bottrill et al. 2012). For protracted applications, the case for dynamic regional designs might seem less compelling. It has been argued that regional conservation objectives are achievable through sequential, single-area investments, making designs unnecessary (Meir et al. 2004). A more realistic argument combines two perspectives. First, single-area investments are necessary to turn designs into reality and can be valid reasons for adapting designs (Table 2, detail in online Appendix). Second, the enduring need for designs is underlined by the difficulty of metrics for single-area investments to address emergent spatial configurations, including those required for broad regional processes (Boyd et al. 2008; Rouget et al. 2006) and context-specific decisions about connectivity (Pressey et al. 2009). Designs are also important for engaging stakeholders, demonstrating what organizations hope to achieve, and testing the costs and feasibility of achieving objectives (Bottrill et al. 2012). Based on the widespread view that 
designs are useful, we explore below the implications of their being, or needing to be, dynamic.

\subsection{Conceptual implications}

If regional designs are dynamic, then how should scientists, decision-makers and stakeholders think about them? One answer is that a regional design is a prediction, by one or more people at a particular time, about the most cost-effective way of achieving a set of explicit conservation objectives. A different group of people would probably interpret the same data, objectives, analytical tools, and context differently and produce a somewhat different design. Regardless, any initial design should be fine-tuned to maximize its feasibility for action (group 1 in Table 2). Over time, data, objectives, and context will change (groups 2 and 3 in Table 2), and designs will need to change accordingly. Recognizing the importance of learning (group 4 in Table 2), it can also be said that any regional design is a step toward a better regional design. These realities lead to the apparent paradox of designs having both importance and transient relevance. Dwight Eisenhower's maxim seems relevant: “ ... plans are useless, but planning is indispensable”. Our interpretation is that the need for any regional design to evolve does not diminish its importance, providing it is seen as part of an adaptive process and has not exceeded its shelf life. Put another way, the choice is not between "grand designs" or "muddling through" (Sayer et al. 2008). Both are needed, recognizing that these terms understate both the adaptive potential of regional designs and the scope to coordinate local actions to achieve wider objectives.

\subsection{Operational implications}

By "operational” we mean the technical, consultative, and logistical aspects of developing regional designs (planning stages 1-9 in Pressey and Bottrill 2009). From all the complexity of the design process, we have summarized the operational implications of dynamic designs as 13 statements (Table 3) that we believe concern the least understood problems and pose the greatest challenges to conservation planners. Only four statements apply to situation 1 , involving rapid application of actions (Table 3). It seems that cross-scale problems, such as the transition from planning units to management units, simply must be resolved when applications are rapid. Rapidly applied designs might also be undertaken at resolutions closer 
to the extents of the resulting actions, thereby streamlining the transition. Importantly, updating rapidly applied designs must typically await a review process, so problems around progressive refinement are not confronted. Only one of our statements applies to situation 3, involving revision of designs (Table 3), and this concerns deciding when and how to revise designs, and what preparations are necessary. Most of our statements (11 of 13) refer to situation 2, involving protracted application (Table 3). This situation, although poorly documented, allows for the fullest expression of a design being "the plan of the day”. Based on our argument that conservation planning will be more cost-effective if designs are progressively updated, situation 2 presents the most questions and unsolved problems.

\subsection{Institutional implications}

The development of regional designs can place intense demands on organizations, but the continuity required to manage the evolution of designs during protracted applications appears so difficult or under-appreciated that it is very rare (but see, for example, Henson et al. 2009). The frequent view that regards designs as endpoints, not first steps in processes of adaptation, has several disadvantages: hard-won data and carefully considered planning become progressively less relevant; capacity and skills are lost, either through outsourcing the required skills or redeployment of planning teams; and outputs, such as priority maps, fail to produce conservation outcomes. Conservation planning has benefits that go beyond implementation of actions, even if effective actions are a primary goal of planning (Bottrill et al. 2012; Bottrill and Pressey 2012). Failing to adjust designs through time to maintain their relevance does not, therefore, negate the benefits of planning, but does substantially reduce them.

Progressive adaptation of regional designs for protracted applications requires updating databases and conservation objectives, redefining regional priorities, and translating these into new actions, all with extensive liaison and explicit protocols; but the context for successful technical management is even more demanding. This context includes (Cowling et al. 2008; Holness and Biggs 2011; Knight et al. 2011a; Sayer et al. 2008): an institutional home for data and the planning process; at least one organization committing to long-term responsibility in steering outputs toward outcomes; establishing and retaining capacity in design, application, and involvement of stakeholders; social learning institutions; conservation and development scenarios developed by stakeholders; collaboration between 
organizations; social marketing; experimental approaches to applying actions; and willingness to confront uncertainty. Among the impediments to embedding these innovations into the institutional context for conservation planning are funding models that value shortterm project outputs over long-term adaptive capacity (Sayer et al. 2008), without counting the costs of failing to adapt designs.

\subsection{Policy implications}

On public land and in marine jurisdictions of developed countries, rapidly applied conservation designs can be seen by politicians and bureaucrats as solutions to conflicts over natural resources, even if some dissatisfaction is inevitable (Kirkpatrick 1998; Osmond et al. 2010). However, designs requiring protracted application, if not avoided because of the political difficulties of dealing with private or community-managed areas, are problematically dynamic. Shifting priorities are not intuitive for municipal planners (Pierce et al. 2005), and the same is probably true for most donors, politicians, agency managers, landholders, and communities. One consequence is the risk of conservation planners losing credibility if their carefully wrought designs appear to be wrong.

An important policy challenge for protracted applications is finding a balance between regional designs and single-area investments such as tender schemes (Stoneham et al. 2003) or community negotiations (Game et al. 2011) that are unlikely to be fully effective without regional designs. Conservation planning has yet to seriously investigate this balance, and the extent to which designs and single-area decisions can be complementary. Until then, it is hard to counter the perception among policy makers and funders that designs are diversions from the real business of applying actions. This view substitutes one set of limitations (of design) with another (of single-area actions). Integration of regional perspectives and local actions, rather than polarization, will probably yield the best outcomes for conservation. Determining outcomes, however, requires more attention to avoided loss of natural assets the ultimate purpose of conservation efforts - and less emphasis on short-term outputs (Bottrill and Pressey 2012) such as designs completed, regardless of application, or actions applied, regardless of their contribution to regional objectives. 


\section{Conclusions}

The weaknesses in methods for conservation planning are most starkly revealed by considering the need to adapt designs during protracted application of actions. The geography concerned - private or community-managed lands and marine waters - is extensive globally and presents the greatest challenges to conservation. Conceptually, and even technically, this is unfamiliar territory for many scientists, as demonstrated by the operational limitations of planning methods listed in this paper. Making regional designs effective for protracted applications also requires institutions and policy to be realigned to accommodate the dynamics of applying actions in strategic ways over extended periods. Our discussions with conservation practitioners lead us to believe that there are more case studies of adapting regional designs during protracted application than indicated by the sparse publications on this topic. A compilation of these case studies and lessons learned would be a valuable contribution.

Adaptive design as described here can be regarded as "scaling down" designs to actions. Meanwhile, initiatives are underway to "scale up" or coordinate actions to better achieve the emergent properties related to regional objectives (Horigue et al. 2012). Given that development of designs and application of local actions often proceed in parallel, but without much integration, it seems clear that scaling down and scaling up will both be needed in many, if not all, regions. We are some way off, however, understanding the circumstances that would favour an emphasis on one approach or the other, whether motivations and funding for the two approaches are well aligned with their effectiveness in particular governance situations, and the extent to which one can succeed without the other.

\section{Acknowledgements}

The first part of the title of this paper was coined by two Brazilian colleagues, Carlos Scaramuzza (WWF-Brasil) and Ricardo Machado (University of Brasilia). Their work on conservation planning in Goiás State, Brazil, required such frequent changes to their regional conservation design that they referred to their design at any time as "the plan of the day". RLP, MM and RW acknowledge the Australian Research Council for funding support. We thank Rodolphe Devillers, Eddie Game, Mary Gleason, Erik Meijaard, Katie Moon, Piero Visconti and Alan White for comments that improved earlier versions of the manuscript. 


\section{References}

Adams, V.M., Pressey, R.L., Naidoo, R., 2010. Opportunity costs: who really pays for conservation? Biological Conservation 143, 439-448.

Agardy, T., 2005. Global marine conservation policy versus site-level implementation: the mismatch of scale and its implications. Marine Ecology Progress Series 300, 242-248.

Álvarez-Romero, J.G., Pressey, R.L., Ban, N.C., Vance-Borland, K., Willer, C., Klein, C.J., Gaines, S.D., 2011. Integrated land-sea planning: the missing links. Annual Review of Ecology, Evolution, and Systematics 42, 381-409.

Armsworth, P.R., Daily, G.C., Kareiva, P., Sanchirico, J.N., 2006. Land market feedbacks can undermine biodiversity conservation. Proceedings of the National Academy of Sciences USA 103, 5403-5408.

Aswani, S., Lauer, M., 2006. Incorporating fishermen's local knowledge and behavior into geographical information systems (GIS) for designing marine protected areas in Oceania. Human Organization 65, 81-102.

Ball, I.R., Possingham, H.P., Watts, M.E., 2009. Marxan and relatives: software for spatial conservation prioritization, In Spatial conservation prioritization: Quantitative methods and computational tools. eds A. Moilanen, K.A. Wilson, H.P. Possingham, pp. 185-195. Oxford University Press, Oxford.

Bottrill, M.C., Mills, M., Pressey, R.L., Game, E.T., Groves, C., 2012. Evaluating perceived benefits of ecoregional assessments. Conservation Biology 26, 851-861.

Bottrill, M.C., Pressey, R.L., 2012. The effectiveness and evaluation of conservation planning. Conservation Letters 5, 407-420.

Boyd, C., Brooks, T.M., Butchart, S.H.M., Edgar, G.J., da Fonseca, G.A.B., Hawkins, F., Hoffmann, M., Sechrest, W., Stuart, S.N., van Dijk, P.P., 2008. Spatial scale and the conservation of biodiversity. Conservation Letters 1, 37-43.

Brewer, T.D., Cinner, J.E., Green, A., Pressey, R.L., 2013. Effects of human population density and proximity to markets on coral reef fishes vulnerable to extinction by fishing. Conservation Biology in press.

Butler, R.A., Koh, L.P., Ghazoul, J., 2009. REDD in the red: palm oil could undermine carbon payment schemes. Conservation Letters 2, 67-73.

Carwardine, J., O'Connor, T., Legge, S., Mackey, B., Possingham, H.P., Martin, T.G., 2012. Prioritizing threat management for biodiversity conservation. Conservation Letters 5, 196204. 
Christie, P., White, A.T., 2007. Best practices for improved governance of coral reef marine protected areas. Coral Reefs 26, 1047-1056.

Cicin-Sain, B., Belfiore, S., 2005. Linking marine protected areas to integrated coastal and ocean management: a review of theory and practice. Ocean and Coastal Management 48, 847-868.

Cinner, J.E., 2007. Designing marine reserves to reflect local socioeconomic conditions: lessons from long-enduring customary management systems. Coral Reefs 26, 1035-1045.

Cowling, R.M., Egoh, B., Knight, A.T., O'Farrell, P.J., Reyers, B., Rouget, M., Roux, D.J., Welz, A., Wilhelm-Rechman, A., 2008. An operational model for mainstreaming ecosystem services for implementation. Proceedings of the National Academy of Sciences USA 105, 9483-9488.

Cowling, R.M., Pressey, R.L., Rouget, M., Lombard, A.T., 2003. A conservation plan for a global biodiversity hotspot - the Cape Floristic Region, South Africa. Biological Conservation 112, 191-216.

Day, J., 2008. The need and practice of monitoring, evaluating and adapting marine planning and management - lessons from the Great Barrier Reef. Marine Policy 32, 823-831.

Day, J.C., 2011. Protecting Australia's Great Barrier Reef. Solutions 2(1), 56-66.

Douvere, F., 2008. The importance of marine spatial planning in advancing ecosystem-based sea use management. Marine Policy 32, 762-771.

Douvere, F., Ehler, C.N., 2011. The importance of monitoring and evaluation in adaptive maritime spatial planning. Journal of Coastal Conservation 15, 305-311.

Finkel, E., 1998. Software helps Australia manage forest debate. Science 281, 1789, 1791.

Gadgil, M., Berkes, F., Folke, C., 1993. Indigenous knowledge for biodiversity conservation. Ambio 22, 151-156.

Game, E.T., Lipsett-Moore, G., Hamilton, R., Peterson, N., Kereseka, J., Atu, W., Watts, M., Possingham, H., 2011. Informed opportunism for conservation planning in the Solomon Islands. Conservation Letters 4, 38-46.

Goodman, P.S., 2003. Assessing management effectiveness and setting priorities in protected areas in KwaZulu-Natal. BioScience 53, 843-850.

Grantham, H.S., Bode, M., McDonald-Madden, E., Game, E.T., Knight, A.T., Possingham, H.P., 2010. Effective conservation planning requires learning and adaptation. Frontiers in Ecology and the Environment 8, 431-437. 
Green, A., Smith, S.E., Lipsett-Moore, G., Groves, C., Peterson, N., Sheppard, S., Lokani, P., Hamilton, R., Almany, J., Aitsi, J., Bualia, L., 2009. Designing a resilient network of marine protected areas for Kimbe Bay, Papua New Guinea. Oryx 43, 488-498.

Groves, C.R., Jensen, D.B., Valutis, L.L., Redford, K.H., Shaffer, M.L., Scott, J.M., Baumgartner, J.V., Higgins, J.V., Beck, M.W., Anderson, M.G., 2002. Planning for biodiversity conservation: putting conservation science into practice. BioScience 52, 499512.

Henson, A., Williams, D., Dupain, J., Gichohi, H., Muruthi, P., 2009. The Heartland Conservation Process: enhancing biodiversity conservation and livelihoods through landscape-scale conservation planning in Africa. Oryx 43, 508-519.

Holness, S.D., Biggs, H.C., 2011. Systematic conservation planning and adaptive management. Koedoe 53(2), Art. \#1029.

Horigue, V., Aliño, P.M., White, A.T., Pressey, R.L., 2012. Marine protected area networks in the Philippines: trends and challenges for establishment and governance. Ocean and Coastal Management 64, 15-26.

Hviding, E., 2006. Knowing and managing biodiversity in the Pacific Islands: challenges of environmentalism in Marovo Lagoon. International Social Science Journal 58, 69-85.

Johannes, R.E., 2002. The renaissance of community-based marine resource management in Oceania. Annual Review of Ecology and Systematics 33, 317-340.

Joppa, L.N., Pfaff, A., 2009. High and far: biases in the location of protected areas. PLoS ONE 4, e8273.

Kapos, V., Balmford, A., Aveling, R., Bubb, P., Carey, P., Entwistle, A., Hopkins, J., Mulliken, T., Safford, R., Stattersfield, A., Walpole, M., Manica, A., 2009. Outcomes, not implementation, predict conservation success. Oryx 43, 336-342.

Kark, S., Levin, N., Grantham, H.S., Possingham, H.P., 2009. Between-country collaboration and consideration of costs increase conservation planning efficiency in the Mediterranean Basin. Proceedings of the National Academy of Sciences USA 106, 15368-15373.

Keppel, G., Morrison, C., Watling, D., Tuiwawa, M.V., Rounds, I.A., 2012. Conservation in tropical Pacific Island countries: why most current approaches are failing. Conservation Letters 5, 256-265.

Kirkpatrick, J.B., 1983. An iterative method for establishing priorities for the selection of nature reserves: an example from Tasmania. Biological Conservation 25, 127-134. 
Kirkpatrick, J.B., 1998. Nature conservation and the Regional Forest Assessment process. Australian Journal of Environmental Management 5, 31-37.

Klein, C.J., Steinback, C., Scholz, A.J., Possingham, H.P., 2008. Effectiveness of marine reserve networks in representing biodiversity and minimizing impact to fishermen: a comparison of two approaches used in California. Conservation Letters 1, 44-51.

Knight, A.T., Cowling, R.M., Boshoff, A.F., Wilson, S.L., Pierce, S.M., 2011a. Walking in STEP: lessons for linking spatial prioritisations to implementation strategies. Biological Conservation 144, 202-211.

Knight, A.T., Cowling, R.M., Campbell, B.M., 2006a. An operational model for implementing conservation action. Conservation Biology 20, 408-419.

Knight, A.T., Cowling, R.M., Difford, M., Campbell, B.M., 2010. Mapping human and social dimensions of conservation opportunity for the scheduling of conservation action on private land. Conservation Biology 24, 1348-1358.

Knight, A.T., Cowling, R.M., Rouget, M., Balmford, A., Lombard, A.T., Campbell, B.M., 2008. Knowing but not doing: selecting priority conservation areas and the researchimplementation gap. Conservation Biology 22, 610-617.

Knight, A.T., Driver, A., Cowling, R.M., Maze, K., Desmet, P.G., Lombard, A.T., Rouget, M., Botha, M.A., Boshoff, A.F., Castley, J.G., Goodman, P.S., MacKinnon, K., Pierce, S.M., Sims-Castley, R., Stewart, W.I., von Hase, A., 2006b. Designing systematic conservation assessments that promote effective implementation: best practice from South Africa. Conservation Biology 20, 739-750.

Knight, A.T., Grantham, H.S., Smith, R.J., McGregor, G.K., Possingham, H.P., Cowling, R.M., 2011b. Land managers' willingness-to-sell defines conservation opportunity for protected area expansion. Biological Conservation 144, 2623-2630.

Lehtomäki, J., Tomppo, E., Kuokkanen, P., Hanski, I., Moilanen, A., 2009. Applying spatial conservation prioritization software and high-resolution GIS data to a national-scale study in forest conservation Forest Ecology and Management 258, 2439-2449.

Lewis, A., Slegers, S., Lowe, D., Muller, L., Fernandes, L., Day, J., 2003. Use of spatial analysis and GIS techniques to re-zone the Great Barrier Reef Marine Park, In Coastal GIS 2003: An integrated approach to Australian coastal issues. eds C.D. Woodroffe, R.A. Furness, pp. 431-451. Centre for Maritime Policy, University of Wollongong, Wollongong.

Margules, C.R., Pressey, R.L., 2000. Systematic conservation planning. Nature 405, 243-253. 
McCook, L.J., Almany, G.R., Berumen, M.L., Day, J.C., Green, A.L., Jones, G.P., Leis, J.M., Planes, S., Russ, G.R., Sale, P.F., Thorrold, S.R., 2009. Management under uncertainty: guide-lines for incorporating connectivity into the protection of coral reefs. Coral Reefs 28, 353-366.

McCook, L.J., Ayling, T., Cappo, M., Choat, J.H., Evans, R.D., de Freitas, D.M., Heupel, M., Hughes, T.P., Jones, G.P., Mapstone, B., Marsh, H., Mills, M., Molloy, F.J., Pitcher, C.R., Pressey, R.L., Russ, G.R., Sutton, S., Sweatman, H., Tobin, R., Wachenfeld, D.R., Williamson, D.H., 2010. Adaptive management of the Great Barrier Reef: a globally significant demonstration of the benefits of networks of marine reserves. Proceedings of the National Academy of Sciences USA 107, 18278-18285.

Meir, E., Andelman, S., Possingham, H.P., 2004. Does conservation planning matter in a dynamic and uncertain world? Ecology Letters 7, 615-622.

Mills, M., Jupiter, S.D., Pressey, R.L., Ban, N.C., Comley, J., 2011. Incorporating effectiveness of community-based management in a national marine gap analysis for Fiji. Conservation Biology 25, 1155-1164.

Mills, M., Pressey, R.L., Ban, N.C., Foale, S., Knight, A.T., Aswani, S., 2013. Understanding characteristics that define the feasibility of conservation actions in a common pool marine resource governance system. Conservation Letters in press.

Mills, M., Pressey, R.L., Weeks, R., Foale, S., Ban, N.C., 2010. A mismatch of scales: challenges in planning for implementation of marine protected areas in the Coral Triangle. Conservation Letters 3, 291-303.

Moilanen, A., 2008. Two paths to a suboptimal solution - once more about optimality in reserve selection. Biological Conservation 141, 1919-1923.

Morrison, J., Loucks, C., Long, B., Wikramanayake, E., 2009. Landscape-scale spatial planning at WWF: a variety of approaches. Oryx 43, 499-507.

Musselwhite, G., Herath, G., 2005. Australia's regional forest agreement process: analysis of the potential and problems. Forest Policy and Economics 7, 579-588.

Naughton, L., 2007. Collaborative land use planning: zoning for conservation and development in protected areas. Land Tenure Center, University of Wisconsin, Tenure Brief No. 4, Madison.

Noss, R.F., 2010. Local priorities can be too parochial for biodiversity. Nature 463, 424. 
Noss, R.F., Carroll, C., Vance-Borland, K., Wuerthner, G., 2002. A multicriteria assessment of the irreplaceability and vulnerability of sites in the Greater Yellowstone Ecosystem. Conservation Biology 16, 895-908.

Osmond, M., Airame, S., Caldwell, M., Day, J., 2010. Lessons for marine conservation planning: a comparison of three marine protected area planning processes. Ocean and Coastal Management 53, 41-51.

Payet, K., Rouget, M., Lagabrielle, E., Esler, K.J., 2010. Measuring the effectiveness of regional conservation assessments at representing biodiversity surrogates at a local scale: a case study in Réunion Island (Indian Ocean). Austral Ecology 35, 121-133.

Pierce, S.M., Cowling, R.M., Knight, A.T., Lombard, A.T., Rouget, M., Wolf, T., 2005. Systematic conservation planning products for land-use planning: interpretation for implementation. Biological Conservation 125, 441-458.

Pomeroy, R., Douvere, F., 2008. The engagement of stakeholders in the marine spatial planning process. Marine Policy 32, 816-822.

Pressey, R.L., 1998. Algorithms, politics and timber: an example of the role of science in a public, political negotiation process over new conservation areas in production forests, In Ecology for everyone: Communicating Ecology to scientists, the public and the politicians. eds R. Wills, R. Hobbs, pp. 73-87. Surrey Beatty and Sons, Sydney.

Pressey, R.L., 2002. The first reserve selection algorithm - a retrospective on Jamie Kirkpatrick's 1983 paper. Progress in Physical Geography 26, 434-441.

Pressey, R.L., Bottrill, M.C., 2008. Opportunism, threats, and the evolution of systematic conservation planning. Conservation Biology 22, 1340-1345.

Pressey, R.L., Bottrill, M.C., 2009. Approaches to landscape- and seascape-scale conservation planning: convergence, contrasts and challenges. Oryx 43, 464-475.

Pressey, R.L., Cabeza, M., Watts, M.E., Cowling, R.M., Wilson, K.A., 2007. Conservation planning in a changing world. Trends in Ecology \& Evolution 22, 583-592.

Pressey, R.L., Cowling, R.M., Rouget, M., 2003. Formulating conservation targets for biodiversity pattern and process in the Cape Floristic Region, South Africa. Biological Conservation 112, 99-127.

Pressey, R.L., Hager, T.C., Ryan, K.M., Schwarz, J., Wall, S., Ferrier, S., Creaser, P.M., 2000. Using abiotic data for conservation assessments over extensive regions: quantitative methods applied across New South Wales, Australia. Biological Conservation 96, 55-82. 
Pressey, R.L., Logan, V.S., 1997. Inside looking out: findings of research on reserve selection relevant to "off-reserve" nature conservation, In Conservation outside Nature reserves. eds P. Hale, D. Lamb, pp. 407-418. University of Queensland, Brisbane.

Pressey, R.L., Logan, V.S., 1998. Size of selection units for future reserves and its influence on actual vs. targeted representation of features: a case study in western New South Wales. Biological Conservation 85, 305-319.

Pressey, R.L., Taffs, K.H., 2001. Scheduling conservation action in production landscapes: priority areas in western New South Wales defined by irreplaceability and vulnerability to vegetation loss. Biological Conservation 100, 355-376.

Pressey, R.L., Watts, M.E., Barrett, T.W., Ridges, M.J., 2009. The C-Plan conservation planning system: origins, applications, and possible futures, In Spatial conservation prioritization: Quantitative methods and computational tools. eds A. Moilanen, K.A. Wilson, H.P. Possingham, pp. 211-234. Oxford University Press, Oxford.

Prober, S.M., Thiele, K.R., Higginson, E., 2001. The Grassy Box Woodlands Conservation Management Network: picking up the pieces in fragmented woodlands. Ecological Management \& Restoration 2, 179-188.

Richardson, E.A., Kaiser, M.J., Edwards-Jones, G., Possingham, H.P., 2006. Sensitivity of marine-reserve design to the spatial resolution of socioeconomic data. Conservation Biology 20, 1191-1202.

Rouget, M., 2003. Measuring conservation value at fine and broad scales: implications for a diverse and fragmented region, the Agulhas Plain. Biological Conservation 112, 217-232.

Rouget, M., Cowling, R.M., Lombard, A.T., Knight, A.T., Kerley, G.I.H., 2006. Designing large-scale conservation corridors for pattern and process. Conservation Biology 20, 549561.

Russ, G.R., Alcala, A.C., 1996. Do marine reserves export adult fish biomass? Evidence from Apo Island, central Philippines. Marine Ecology Progress Series 132, 1-9.

Sayer, J., Bull, G., Elliott, C., 2008. Mediating forest transitions: 'grand design' or 'muddling through'. Conservation and Society 7, 320-327.

Scott, J.M., Davis, F.W., McGhie, R.G., Wright, R.G., Groves, C., Estes, J., 2001. Nature reserves: do they capture the full range of America's biological diversity? Ecological Applications 11, 999-1007. 
Seddon, J.A., Barrett, T.W., Love, J., Drielsma, M., Briggs, S.V., Gibbons, P., Ferrier, S., 2010. Linking site and regional scales of biodiversity assessment for delivery of conservation incentive payments. Conservation Letters 3, 415-424.

Smith, R.J., Verissimo, D., Leader-Williams, N., Cowling, R.M., Knight, A.T., 2009. Let the locals lead. Nature 462, 280-281.

Spring, D., Baum, J., Mac Nally, R., MacKenzie, M., Sanchez-Azofeifa, A., Thomson, J.R., 2010. Building a regionally connected reserve network in a changing and uncertain world. Conservation Biology 24, 691-700.

Stokes, E.J., Strindberg, S., Bakabana, P.C., Elkan, P.W., Iyenguet, F.C., Madzoké, B., Malanda, G.A.F., Mowawa, B.S., Moukoumbou, C., Ouakabadio, F.K., Rainey, H.J., 2010. Monitoring great ape and elephant abundance at large spatial scales: measuring effectiveness of a conservation landscape. PLoS ONE 5, e10294.

Stoneham, G., Chaudhri, V., Ha, A., Strappazzon, L., 2003. Auctions for conservation contracts: an empirical examination of Victoria's BushTender trial. Australian Journal of Agricultural and Resource Economics 47, 477-500.

Syakur, A., Wibowo, J.T., Firmansyah, F., Azam, I., Linkie, M., 2012. Ensuring local stakeholder support for marine conservation: establishing a locally managed marine area network in Aceh. Oryx 46, 516-524.

Turner, W.R., Wilcove, D.S., 2006. Adaptive decision rules for the acquisition of nature reserves. Conservation Biology 20, 527-537.

van de Geer, C., Mills, M., Adams, V.M., Pressey, R.L., McPhee, D., 2013. Impacts of the Moreton Bay Marine Park rezoning on commercial fishermen. Marine Policy 39, 248-256.

Vane-Wright, R.I., 1996. Identifying priorities for the conservation of biodiversity: systematic biological criteria within a socio-political framework, In Biodiversity: a biology of numbers and difference. ed. K.J. Gaston, pp. 309-344. Blackwell Science, Oxford.

Visconti, P., Pressey, R.L., Segan, D.B., Wintle, B.A., 2010. Conservation planning with dynamic threats: the role of spatial design and priority setting for species' persistence. Biological Conservation 143, 756-767.

von Hase, A., Rouget, M., Cowling, R.M., 2010. Evaluating private land conservation in the Cape Lowlands, South Africa. Conservation Biology 5, 1182-1189.

Watts, M.E., Ball, I.R., Stewart, R.S., Klein, C.J., Wilson, K., Steinback, C., Lourival, R., Kircher, L., Possingham, H.P., 2009. Marxan with Zones: software for optimal 
conservation based land- and sea-use zoning. Environmental Modelling \& Software 24, 1513-1521.

Weeks, R., Jupiter, S.D., 2013. Adaptive co-management of a marine protected area network in Fiji. Conservation Biology in press.

Weeks, R., Russ, G.R., Alcala, A.C., White, A.T., 2010a. Effectiveness of marine protected areas in the Philippines for biodiversity conservation. Conservation Biology 24, 531-540.

Weeks, R., Russ, G.R., Bucol, A.A., Alcala, A.C., 2010b. Incorporating local tenure in the systematic design of marine protected area networks. Conservation Letters 3, 445-453.

Weeks, R., Russ, G.R., Bucol, A.A., Alcala, A.C., 2010c. Shortcuts for marine conservation planning: the effectiveness of socioeconomic data surrogates. Biological Conservation 143, 1236-1244.

Wilcove, D.S., Bean, M.J., Long, B., Snape, W.J., Beehler, B.M., Eisenberg, J., 2004. The private side of conservation. Frontiers in Ecology and the Environment 2, 326-327.

Wilhelm-Rechman, A., Cowling, R.M., 2011. Framing biodiversity conservation for decision makers: insights from four South African municipalities. Conservation Letters 4, 73-80.

Wilson, K.A., Underwood, E.C., Morrison, S.A., Klausmeyer, K.R., Murdoch, W.W., Reyers, B., Wardell-Johnson, G., Marquet, P.A., Rundel, P.W., McBride, M.F., Pressey, R.L., Bode, M., Hoekstra, J.M., Andelman, S., Looker, M., Rondinini, C., Kareiva, P., Shaw, M.R., Possingham, H.P., 2007. Conserving biodiversity efficiently: what to do, where, and when. PLoS Biology 5, 1850-1861. 
Table 1

Glossary of important terms used in the text, Table 2, and online Appendix

\begin{tabular}{|c|c|}
\hline Term & Definition in this paper \\
\hline Actions & $\begin{array}{l}\text { Spatially explicit interventions to mitigate the effects of threatening } \\
\text { processes on biodiversity features. Actions include strict reservation, a } \\
\text { wide variety of off-reserve arrangements, including zonings, that combine } \\
\text { conservation management and extractive uses, and restoration. }\end{array}$ \\
\hline Conservation areas & $\begin{array}{l}\text { Tracts of land, sea or fresh water identified as having potential for actions } \\
\text { (consisting of one or more planning units) or where actions have been } \\
\text { applied (consisting of one or more management units). }\end{array}$ \\
\hline Designs & $\begin{array}{l}\text { Configurations of notional conservation areas, often including already } \\
\text { established conservation areas. }\end{array}$ \\
\hline Local & $\begin{array}{l}\text { The spatial extent of actions varies widely, but we focus particularly on } \\
\text { small areas of private land or locally managed coastal waters ranging from } \\
10^{-3} \text { to } 10^{0} \mathrm{~km}^{2} \text { (Prober et al. 2001; Weeks et al. 2010a) and areas between } \\
10^{-1} \text { and } 10^{1} \mathrm{~km}^{2} \text { assembled into larger terrestrial reserves or marine no- } \\
\text { take zones (Lewis et al. 2003; Pressey et al. 2009). }\end{array}$ \\
\hline Management units & $\begin{array}{l}\text { Spatial units where one or more actions are to be applied or have been } \\
\text { applied. }\end{array}$ \\
\hline Objectives & $\begin{array}{l}\text { Statements of desired outcomes of designs, often quantitative but } \\
\text { sometimes also qualitative. Objectives derive from values via goals } \\
\text { (Pressey and Bottrill 2009) but are constrained by available data. In } \\
\text { systematic approaches to conservation design, regional objectives are } \\
\text { defined for representation and persistence of features (e.g. species, } \\
\text { vegetation types, marine ecosystems) recorded in regional data sets; but } \\
\text { objectives can also be defined locally, by various stakeholders, for only } \\
\text { small parts of regions. }\end{array}$ \\
\hline Planning units & $\begin{array}{l}\text { Spatial units of assessment and comparison for conservation designs, often } \\
\text { defined arbitrarily as hexagons or square grids, but also as sub- } \\
\text { catchments, vegetation fragments, or ownership parcels, or some mixture } \\
\text { of these. We use the term here to refer also to groups of planning units that } \\
\text { have been clustered for various reasons. }\end{array}$ \\
\hline Regional & $\begin{array}{l}\text { The extents of regions, or planning domains, vary widely. Typically, } \\
\text { regions include ecoregions or large jurisdictions in the order of } 10^{3} \text { or } 10^{4} \\
\mathrm{~km}^{2} \text {, but can involve more localized assessments in the order of } 10^{2} \mathrm{~km}^{2} \\
\text { bounded physically (Green et al. 2009) or by small jurisdictions } \\
\text { (Wilhelm-Rechman and Cowling 2011). }\end{array}$ \\
\hline
\end{tabular}




\section{Table 2}

Some reasons for changes to regional designs in relation to three planning situations (see Table 1 for glossary of key terms and online Appendix for an extended explanation of each reason). We have arranged reasons in four groups: 1 . Early fine-tuning - adjustments to regional designs to facilitate application of actions; 2. Mistakes and surprises - related to errors in data and unforeseen constraints and opportunities; 3. New data collected by the planning team or others; and 4. Major overhaul - reassessments of objectives, approaches to design, planning approaches, and planning context. For rapidly applied actions, the filled squares $(\boldsymbol{\square})$ indicate reasons that will apply to any regional design, and the open squares ( $\square$ ) indicate reasons that might apply to extended design processes (e.g. several years of refinement of the design for the rezoning of the Great Barrier Reef Marine Park). For protracted applications of actions, all reasons in groups 1-3 are likely to apply, but it is debatable (especially with so few case studies) whether reasons in group 4 would more realistically motivate fully revised designs. Revised designs, which can follow previous designs applied either rapidly or over long periods, are likely to be motivated by reasons in groups 3 and 4 . Reasons in group 1 will probably be important for any revised design. The importance of reasons in group 2 for revised designs will depend on two factors: the potential for adaptive management (e.g. adjustment of actions) without altering the previous design's overall configuration; and the duration of the new design process and whether actions are rapid or protracted, assuming that mistakes and surprises detected in the period between the designs will be incorporated into new data sets. 
1. Early fine-tuning

Substitution of selected planning units for improved feasibility

Transition from automated to context-specific configuration

Transition from planning units to management units

2. Mistakes and surprises $\quad$ Errors in biodiversity data used for regional design

Errors in cost data used for regional design

Errors in threat data used for regional design

Unforeseen opportunities for conservation actions

Unforeseen constraints on conservation actions

Additional, locally relevant objectives important to stakeholders

Conservation actions unrelated to regional design

\begin{tabular}{lll}
$\mathbf{\square}$ & $\mathbf{\square}$ & $\mathbf{0}$ \\
$\mathbf{\square}$ & $\mathbf{\square}$ & $\mathbf{0}$ \\
\hline$\square$ & $\mathbf{\square}$ & $\square$ \\
$\square$ & $\mathbf{\square}$ & $\square$ \\
$\square$ & $\mathbf{\square}$ & $\square$ \\
$\square$ & $\mathbf{\square}$ & $\square$ \\
$\square$ & $\mathbf{\square}$ & $\square$ \\
$\square$ & $\mathbf{\square}$ & $\square$ \\
$\square$ & $\mathbf{\square}$ & $\square$
\end{tabular}

3. New data

New data on biodiversity

New data on costs

New data on threats

New data on climate change and its effects

$\square$
$\square$
$\square$
$\square$

(

च

-

Revised regional conservation objectives

$\square$

Learning to develop better regional designs

Changed social, economic, governance, or political contexts 


\section{Table 3}

Operational implications of dynamic regional designs. Numbered columns refer to planning situations: 1 . rapid application of actions; 2. protracted application of actions; and 3. revision of regional designs. Shading indicates the planning situation(s) for which the statement is most relevant.

\section{Pros and cons of mandated minimum review intervals}

Among the advantages of mandated minimum review intervals are certainty for industries reliant on natural resources (Musselwhite and Herath 2005) and increased likelihood of realizing benefits of conservation actions that take time to manifest (e.g. spillover of adult fish biomass from marine reserves, Russ and Alcala 1996). However, regional designs with rapid application of actions have limited potential to adjust to the mistakes and surprises that become evident during protracted applications. If rapidly applied designs are also “frozen” by mandated minimum review intervals, then mistakes are locked in and adaptation is limited to fine-tuning (Day 2008). Minimum review intervals can therefore have undesirable implications for biodiversity when the conservation requirements of important species or other features are underestimated. This highlights the greater need, when developing designs that will be applied rapidly and inflexibly, for investment in data, consultation among stakeholders, and objectives that err on the side of overestimating conservation requirements.

\section{Caution in extrapolating between situations}

Widely cited success stories in applying regional designs, such as the Regional Forest Agreement process in New South Wales (Finkel 1998) and the rezoning of the Great Barrier Reef Marine Park (Day 2011) come from rapid applications of actions on public land or in marine regions with uncomplicated tenure and governance. These exercises are not easily applicable to the challenges of protracted application on private land or in near-shore marine waters in developing countries with finely subdivided ownership and responsibility for management. More generally, authors familiar with conservation management in developing countries have warned against naïve attempts to duplicate planning approaches formulated in different, and often less complicated, social and political circumstances (Christie and White 2007; Cinner 2007; Hviding 2006; Keppel et al. 2012). 


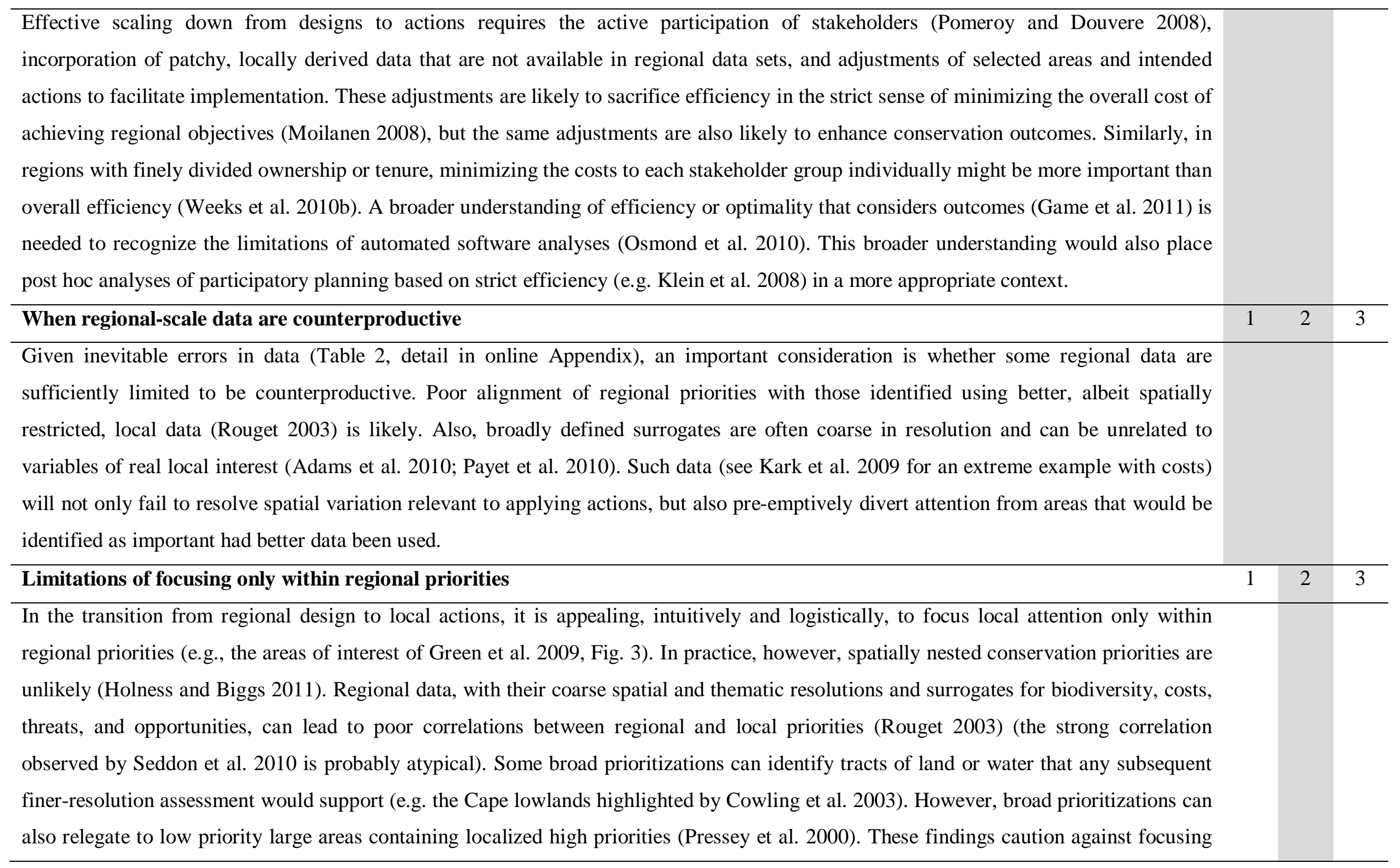


only within regional priority areas when designs are scaled down to local actions. Planners should expect some important local priorities to be misaligned with regional priorities. With experience of particular regions, prediction of local priorities outside regional focal areas might be possible.

\begin{tabular}{|c|c|c|c|}
\hline Anticipating required changes to regional designs & 1 & 2 & 3 \\
\hline $\begin{array}{l}\text { Approaches to managing the mistakes and surprises inherent in protracted application are poorly developed and illustrated by very few } \\
\text { case studies. Monitoring of adjustments to designs during protracted application is so rare that it is difficult for planners even to anticipate } \\
\text { the extent to which designs might have to change. Factors likely to influence the extent of required changes include the differences } \\
\text { between resolutions of regional and local data, the informativeness of regional-scale surrogates for biodiversity, costs, threats and other } \\
\text { variables (online Appendix), and the socio-political settings in which actions are applied. Some understanding of the influence of these and } \\
\text { other factors on the dynamics of regional designs can be gained from desktop studies, but much will depend on a deeper appreciation of } \\
\text { the practice of applying and adapting regional designs through time. }\end{array}$ & & & \\
\hline Minimizing required changes to regional designs & 1 & 2 & 3 \\
\hline
\end{tabular}

While changes to regional designs during protracted applications hardly seem avoidable (e.g. group 2 in Table 2), they might be minimized. Potential benefits of minimizing these changes include enhancing the credibility of designs, reducing the duration and expense of transitions from designs to actions, and reducing the number of local priorities missed through focusing within misconstrued regional priorities. Ways of minimizing adjustments of designs include: close involvement of local communities, experts, and implementing organizations (Game et al. 2011; Knight et al. 2011a); aligning planning units with management units (Weeks et al. 2010b); better understanding of conservation opportunities (Knight et al. 2010; Mills et al. 2013); and avoiding surrogates likely to be remote from local variables of real interest. Intuitively, there is a balance between investing in designs that minimize later adjustments to actions and investing in the adjustments themselves. This trade-off is poorly understood.

\section{Decision support for dynamic designs}

While decision support tools with graphic interfaces have underpinned participatory regional design since 1996 (Pressey 1998) and are now widely applied (Lehtomäki et al. 2009; Pressey et al. 2009), these tools have a poorly explored but crucial role in managing 
progressive adjustments to designs during protracted applications. Interactive software can reconfigure designs, monitor achievement of objectives, and illustrate tradeoffs between objectives and between cost-efficiency and stakeholder preferences (Game et al. 2011). A review of the interactive functionality from existing tools could lay the foundation for more effective software to manage protracted applications.

Pros and cons of action-specific designs

Recent advances in design include spatially explicit allocation of different actions (Watts et al. 2009; Wilson et al. 2007). While these methods are subject to the same adjustments as generic designs (Table 2), they involve additional estimates and assumptions that could increase the need for adaptation: 1 . the relative costs of actions, likely to vary spatially in ways that are difficult to predict from regional data; 2. variation between ecosystems in relative effectiveness of actions (Mills et al. 2011); and 3. opportunities for particular actions, only rarely observed directly and then across very small sets of planning units (Aswani and Lauer 2006; Knight et al. 2011b), with prediction across regions inevitably error-prone. The potential for mistakes and surprises in attempting to apply multiple-action designs is illustrated by a recent study (Carwardine et al. 2012) covering five large bioregions in north-western Australia. The authors identified priorities for actions across entire bioregions based on estimates of the effects of threats and management actions on the persistence of species and the costs and feasibilities of actions, with no guidance on spatial heterogeneity of cost-effectiveness of actions within bioregions. Overall, there is a poor understanding of the respective merits of action-specific and generic conservation design in the context of protracted application and adjustment to local data, constraints and opportunities.

\begin{tabular}{l}
\hline Getting better at scheduling \\
\hline Moving from regional design to protracted local actions implies spatial and temporal prioritization to identify parts of designs that will be \\
considered first for application. The need for strategic priorities underlines the value of the growing literature on scheduling actions in the \\
face of parallel, incremental conservation and attrition of biodiversity. This need also highlights the unresolved issues around balancing \\
different aspects of biodiversity (Pressey et al. 2007) and balancing biodiversity value, threat, and opportunities for action (Game et al. \\
2011; Seddon et al. 2010). \\
\hline Measuring effectiveness of dynamic designs
\end{tabular}




\begin{abstract}
The need for regional designs to adapt has implications for evaluating planning effectiveness. If designs must change during application, then measuring their effectiveness in guiding implementation (Knight et al. 2008) should recognize that spatial congruence between initial regional priorities and eventual applied actions can underestimate the influence of designs (and see Fig. 5A). More broadly, conservation gains can be mediated by outcomes other than spatial implementation (Kapos et al. 2009), and evaluation should address aspects of financial, social, human and institutional, as well as natural, capital (Bottrill and Pressey 2012), many of which are insensitive to changes in the configurations of designs.
\end{abstract}

\title{
Mainstreaming dynamic designs
}

Progressively adapted designs also pose challenges to mainstreaming, or interpreting technical outputs for planning and development sectors (Cowling et al. 2008; Pierce et al. 2005). Mainstreaming products must account for initial designs changing unpredictably. One option for doing this is to specify regional priorities as specific selected areas (e.g. land parcels) only if they are unlikely to change. Another option, when priorities for specific areas are likely to be dynamic (e.g. as data on costs and opportunities are updated) is to link guidelines to features such as vegetation types, the relative priority of which is likely to change less than that of individual selected areas. It might also be possible to synchronize revisions of designs with mandated revisions of statutory regional and local plans.

\section{Deciding when and how to revise designs}

Case studies of designs being revised are hard to find. What should trigger revisions? For mandated maximum review intervals (20 years in the case of the Regional Forest Agreements in Australia, Musselwhite and Herath 2005), the answer is straightforward, but that does not necessarily mean that planners will be ready to develop the new designs. Being ready requires a well established monitoring program and an approach to evaluating the effectiveness of designs and related actions. Such programs and approaches are rare (Douvere and Ehler 2011) and criteria for the effectiveness of designs are poorly understood (Bottrill and Pressey 2012), although there are models to build on (McCook et al. 2010; Stokes et al. 2010). Being ready also means understanding how to overcome the limitations of previous designs. These limitations might be readily apparent, as in the broad extent and coarse resolution of the 2002 design for the Cape Floristic Region (which motivated the Cape Lowlands Conservation Plan, von Hase et al. 2010). Ideally, however, limitations will be addressed by adapting new ideas about data, ecosystem dynamics, socio-economic considerations, and quantitative objectives to the regions in question. 
In the absence of mandated review intervals, monitoring, evaluation and adaptation of new ideas remain crucial, but planners will have to judge when designs should be revised (group 4 in Table 2), and there appear to be no guidelines. 
Fig. 1. Progressive refinement of part of the regional design for the rezoning of the Great Barrier Reef Marine Park, implemented in 2004. The eastern red line is the outer boundary of the Marine Park. Outlines of reefs and islands are shown in dark blue. A, Output from conservation planning software alone, showing clusters of selected planning units in red indicating potential no-take areas (see Lewis et al. 2003 for technical details). This configuration is from one of the later software iterations in early 2003. B, Mid-2003, draft zoning plan released for public comment, including identification of multiple zones and adjustments of zone boundaries refined for ease of field navigation; C, Mid-2004, final zoning plan, showing further adjustments of zones to deal with new data, including further information from public consultation. Zone colours: green $=$ no-take; yellow $=$ limited fishing; mid blue = benthic habitat protection (including prohibition of trawling); pale blue = general use. Map courtesy of the Spatial Data Centre, Great Barrier Reef Marine Park Authority, 2010.
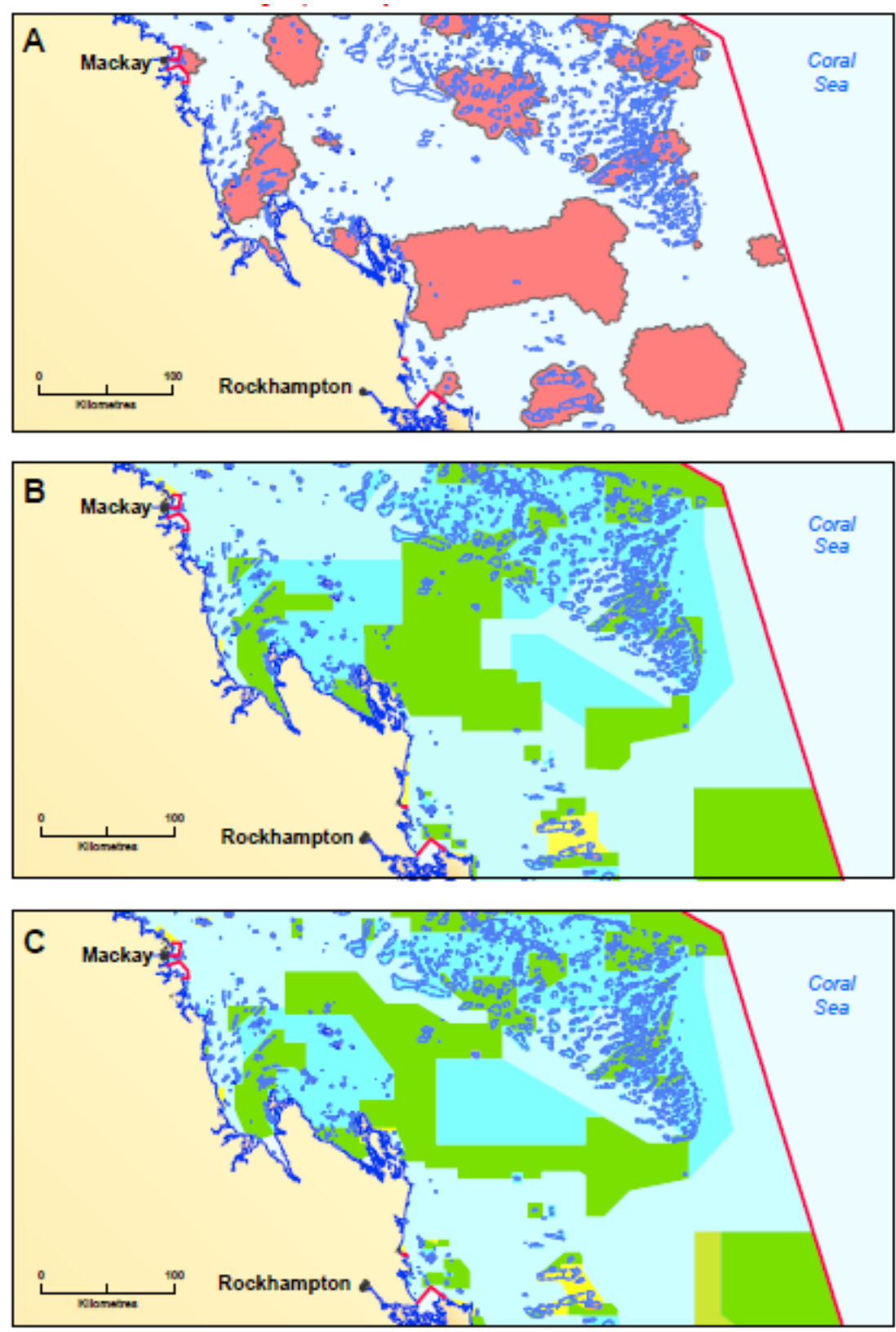
Fig. 2. Hypothetical iterations between regional design and local actions during protracted application. A, Hexagonal planning units initially identified during regional design as potential priorities for conservation (red), overlaid on irregular management units with boundaries that, typically, are unrelated to those of planning units. The large block of selected planning units in the left of the panel has been identified as a regional priority for action. $\mathrm{B}$, First round of changes to the regional design, after consultation with local communities and ground-truthing, followed by correction of the regional data sets. Some management units have been matched to specific, feasible conservation actions (green) while others are identified as unavailable or unsuitable for conservation actions (grey). Any of the reasons grouped under early fine-tuning or mistakes and surprises in Table 2 could be responsible for these changes. C, With green areas now locked into the regional design and grey areas locked out, regional priorities have been recalculated to reflect changes in achievement of objectives due to modifications of the design in B. Changes to the initial configuration of priority planning units in the left of the panel have propagated to some other areas. D, A second round of adaptation of the design, with local actions allocated to additional areas and one more management unit identified as unsuitable. As well, one area previously excluded (*, white) has become available for conservation action, but is not required at this time. Another area * $^{*}$ green) has been identified by local experts, on the basis of condition and species occurrences not recorded in the regional database, as a desirable connection between management units. 


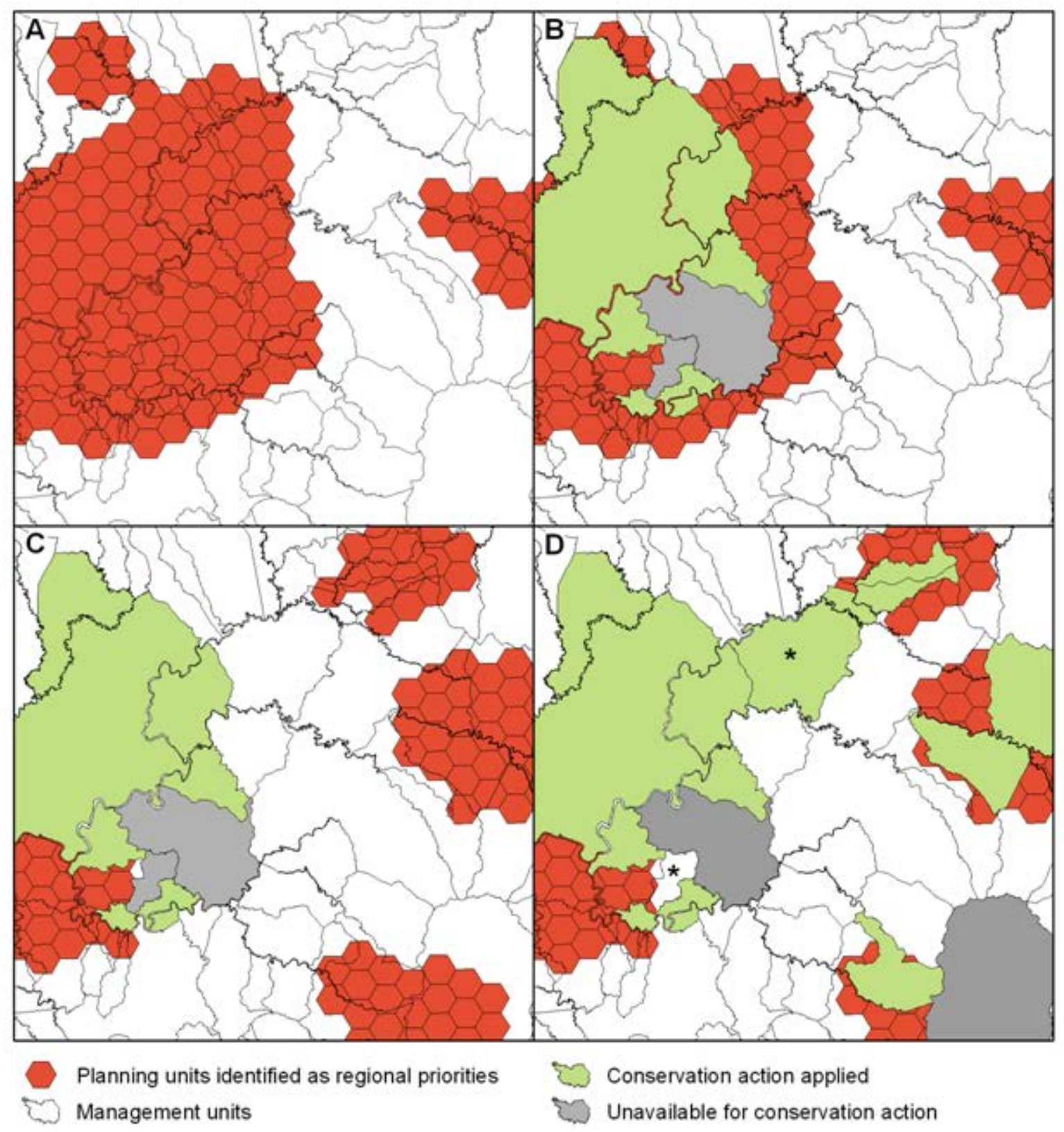


Fig. 3. Transition from planning units to management units in Kimbe Bay. A, Location of Kimbe Bay within Papua New Guinea. B, Boundaries of the Kimbe Bay planning region (pink) adjacent to land (green) with areas of interest identified by Green et al. (2009) surrounded by dashed lines. The areas of interest were generalized from clusters of hexagonal planning units (each about 10 ha) having high selection frequency in Marxan analyses, with boundaries of areas of interest also adjusted according to the local knowledge of members of the planning team. The yellow box surrounds the Tarobi area of interest. C, Tarobi locally managed marine area (yellow), which includes a variety of management actions including restricted use areas (white) and no-take areas (orange). Note that, in a dynamic design exercise, the sparse application of actions in the Tarobi area of interest would warrant design changes to the boundaries of Tarobi, perhaps complemented by modification of other areas of interest and the identification of new ones. Data courtesy of The Nature Conservancy's IndoPacific Resource Centre.

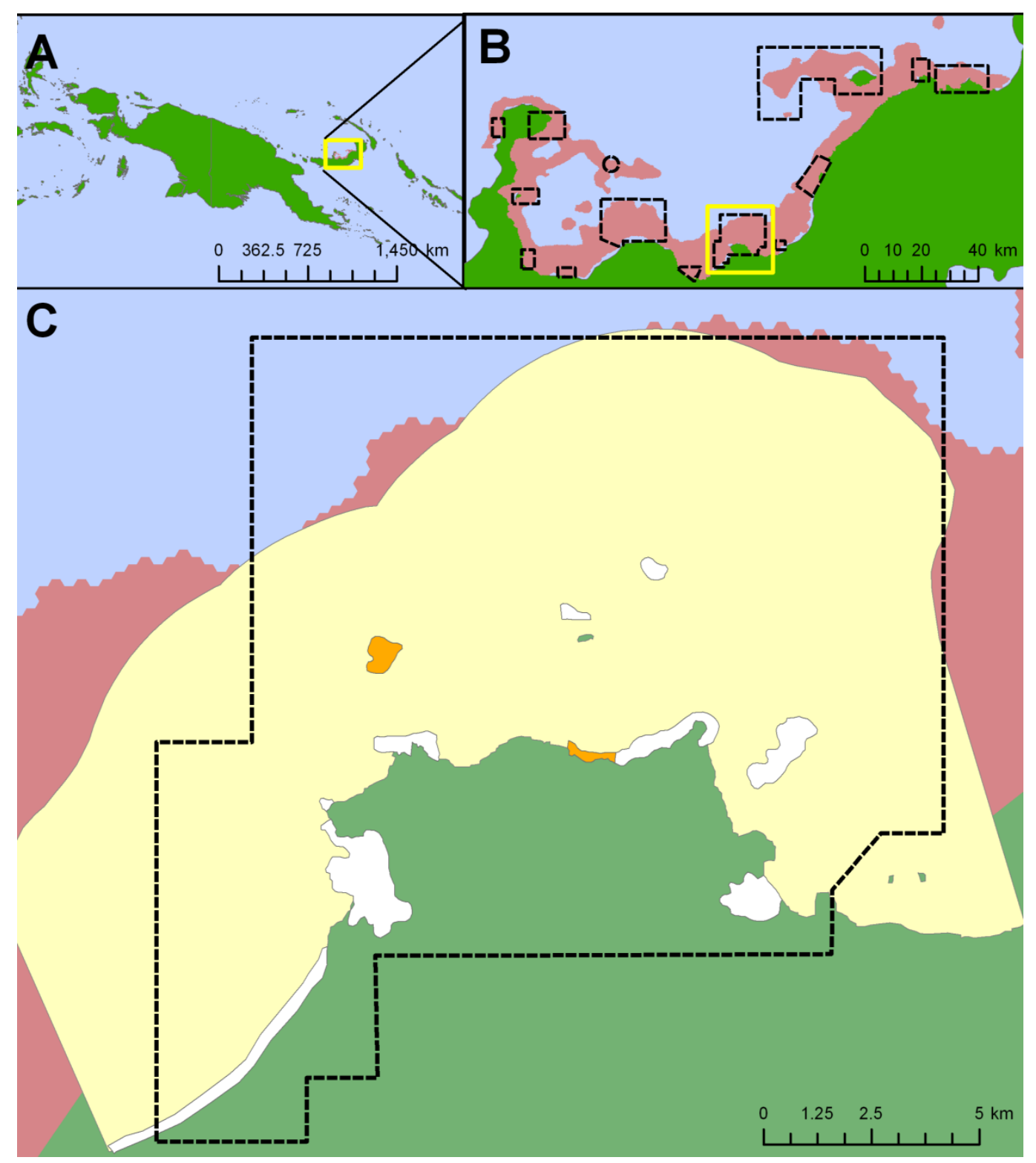


Fig. 4. Refinement by experts of regional conservation design in Queensland, representing the early parts of a protracted process of applying conservation actions. The map is centred on the northern section of the Central Mackay Coast bioregion. Pale blue is ocean. Dark grey is the neighbouring Brigalow Belt North bioregion. Grey lines delineate the cadastral parcels used as planning units. Dark blue parcels are existing conservation reserves incorporated by default into all regional designs shown in this figure. A, Green areas were selected with a state-wide application of Marxan software (Ball et al. 2009) to achieve quantitative objectives for regional ecosystems $(n=1,339)$ while minimizing costs estimated using unimproved capital land values. B, Output from the conservation planning software C-Plan showing categories of summed irreplaceability (Pressey et al. 2009). Together with the Marxan selections, this was the starting point for expert-based, interactive conservation design at a workshop held in Rockhampton in February 2011, attended by representatives of local natural resource management groups and state government staff representing Queensland Parks and Wildlife, the Queensland Herbarium, and the Queensland Nature Refuge Program. C, Final output from the workshop with new priority areas for conservation actions shown in dark green. Pale grey areas were excluded from further consideration because of poor condition and management liabilities. D, Post-workshop changes to priority areas for actions, including the addition of remaining areas in State Forest and the Shoalwater Bay Military Training Area. Map courtesy of Craig Hempel, Queensland Department of Environment and Resource Management, 2011. 


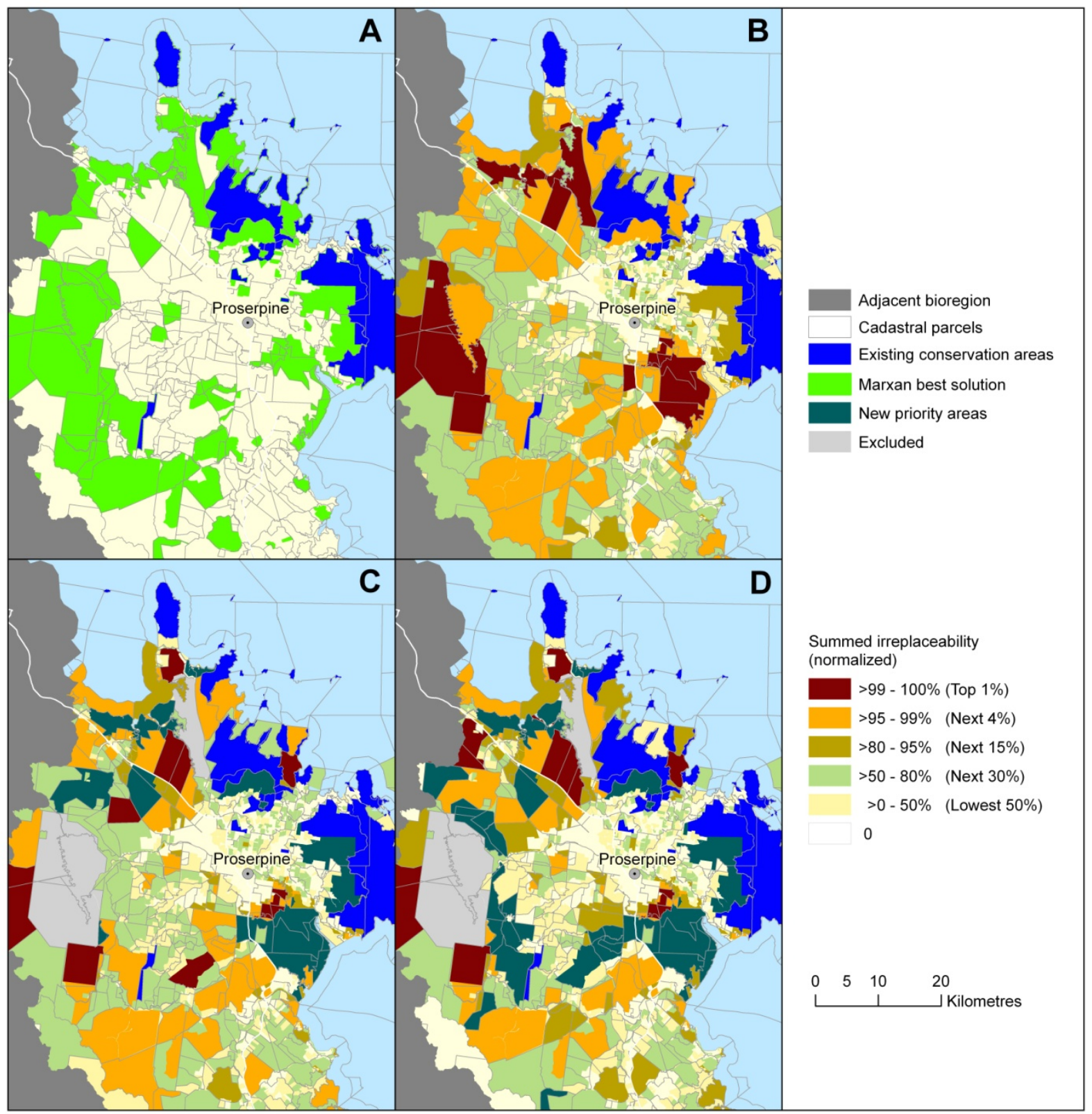


Fig. 5. Designs and actions in the Cape Floristic Region, South Africa. The black line bounds the study region for the 2002 regional conservation plan developed by Cowling et al. (2003). Information on all post-2002 conservation actions and conservation designs was obtained from the Biodiversity GIS website (www.sanbi.org). A, Conservation actions subsequent to the regional design of 2002. Green areas are protected areas established before, and included in, the 2002 planning exercise. Orange areas are planning units, mostly grid squares of approximately $40 \mathrm{~km}^{2}$, identified by Cowling et al. (2003) as constituting the initial regional design. Other colours indicate subsequent conservation actions either intersecting the 2002 priority areas (blue) or outside them (pink). Actions include protected areas, private nature reserves, and stewardship areas/conservancies. B, Nine conservation designs subsequent to the regional design of 2002. 
A.

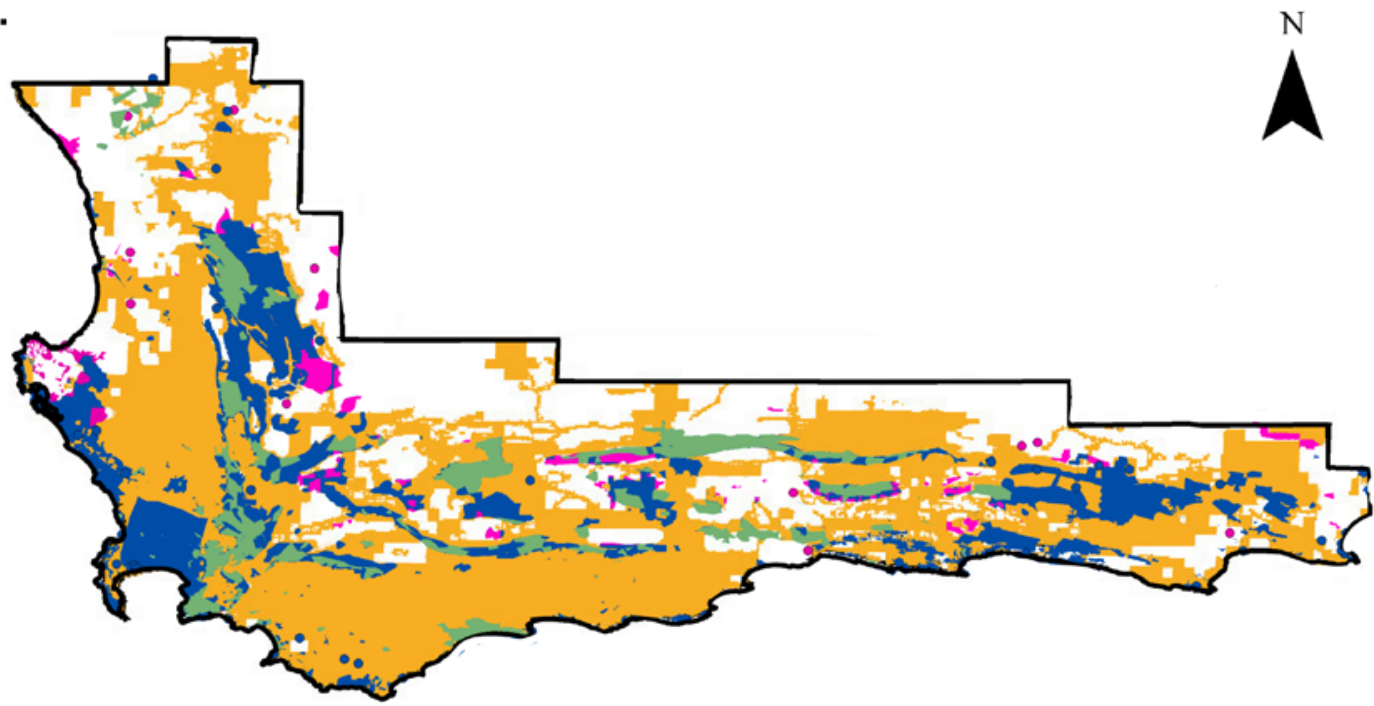

Protected areas established before 2002 regional plan

Priority areas identified in the 2002 regional plan

Post-2002 conservation actions within 2002 priority areas

Post-2002 conservation actions outside 2002 priority areas

\section{B}

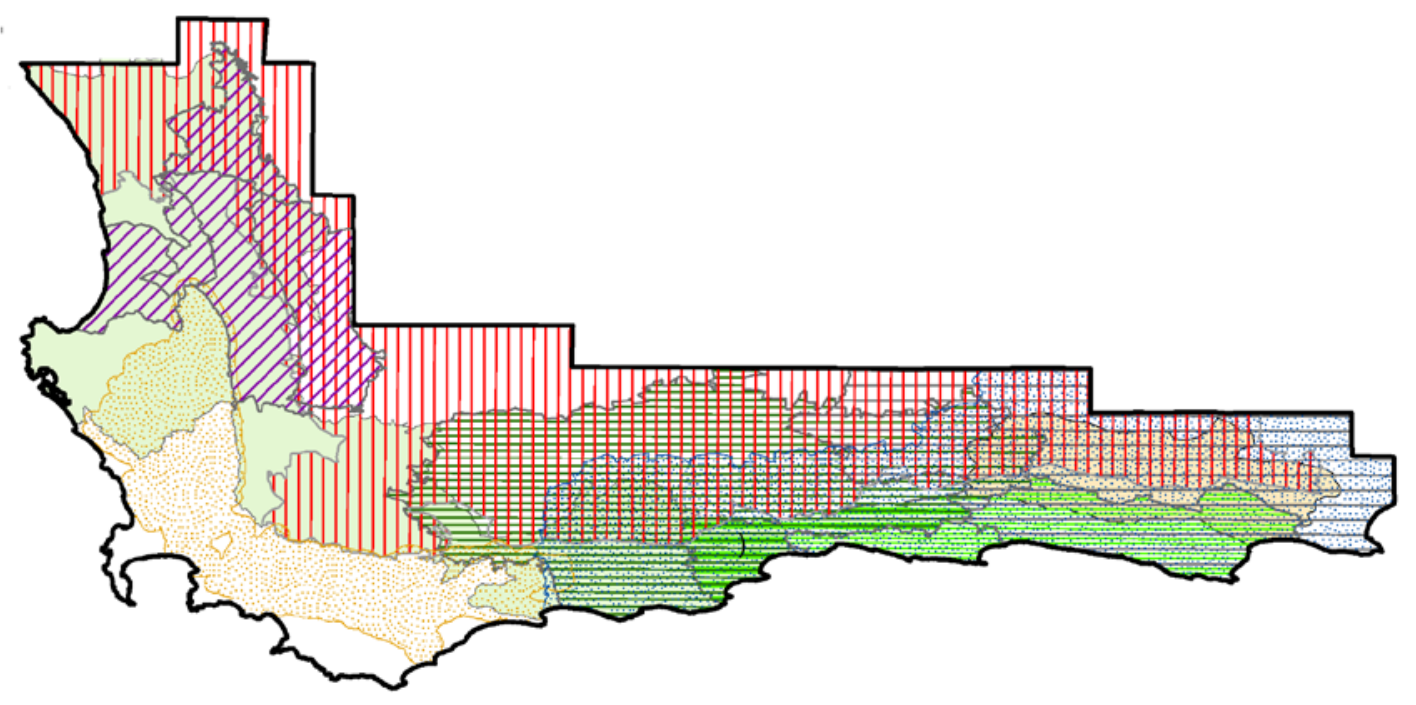

Subtropical Thicket Ecosystem Project (2003) Cape Lowlands Renosterveld (2003)

WIII Succulent Karoo Ecosystem Programme (2003) Gouritz Initiative (2004)

Greater Cederberg Biodiversity Corridor (2005)

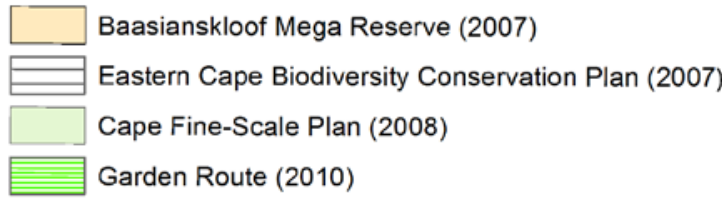

Garden Route (2010)

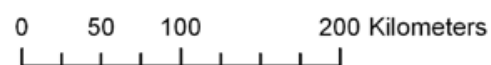

